\title{
Plutonium, protactinium, uranium and thorium isotopes determination in environmental samples by SF ICP-MS
}

\author{
M. Agarande ${ }^{1}$, S. Schmidt ${ }^{2}$, A.M. Neiva-Marques ${ }^{1}$ and P. Bouisset ${ }^{1}$ \\ ${ }^{1}$ Institut de Radioprotection et de Sûreté Nucléaire, Bâtiment 501, Bois des Rames, \\ 91400 Orsay, France \\ ${ }^{2}$ UMR 5805 EPOC, Département de Géologie et d'Océanographie, 33405 Talence, France
}

\begin{abstract}
Alpha spectrometry is the most commonly used analytical tool for the determination of Pu, Am, $\mathrm{Pa}, \mathrm{U}$ and Th long live radionuclides. Thermal ionization mass spectrometry (TIMS) and acceleration mass spectrometry (AMS) are also still considered as primary methods for the determination of their isotope ratios. Spectrometers with plasma ion sources now offer another efficient alternative method with the development of sector field inductively coupled plasma mass spectrometry (SF ICP-MS). This paper summarizes the development work performed and results obtained using this technique for the analysis of such radionuclides.

Isotopic ratios and ultra trace levels of man made radionuclides like 239, 240, 241 plutonium but also naturally occurring species like 231 protactinium, 234, 235, 238 uranium and 230, 232 thorium were determined in different field samples and reference materials using a micro concentric nebulizer as an introduction system for the mass spectrometer. Prior to the mass spectrometric measurements these elements were isolated from major elements by different selective precipitations. In further steps, they were purified by anion exchange. Results of isotope ratios including plutonium ones are also discussed.
\end{abstract}

\section{INTRODUCTION}

Over the last decades there was an important increase in public concern regarding environmental issues, consequently studies about radioactive contamination of the environment have become a major subject for many scientific researches. Due to their high biological toxicity and their long half-lives, alpha emitters, both naturally occurring (U, Th, Pa) as well as from anthropogenic sources (Pu, Am), are of primary interest for such studies. The determination of these radionuclides is usually performed by alpha spectrometry, which requires complex chemical separation procedures prior to time-consuming measurement routines. ${ }^{241} \mathrm{Am}$ can also be measured by direct gamma spectrometry but in most environmental matrices its concentration is too low to permit direct measurement [1]. ${ }^{241} \mathrm{Pu}$, the pure beta emitting nuclide of $\mathrm{Pu}$, is usually performed by liquid scintillation [2].

In the early eighties, inductively coupled plasma mass spectrometers were available and ten years later, the development of spectrometers equipped with sector field as mass filters could offer another tool for the determination of sub pg. $\mathrm{kg}^{-1}$ range of long-lived radionuclides in environmental samples [3, 4, 5].

Naturally occurring radionuclides of $U$ and Th- series are often retained to study processes in the ocean because of their well-known sources [6]. In particular, the difference in particle reactivity of two radionuclides, ${ }^{231} \mathrm{~Pa}\left(\mathrm{~T}_{1 / 2}=32500 \mathrm{y}\right)$ and ${ }^{230} \mathrm{Th}\left(\mathrm{T}_{1 / 2}=75400 \mathrm{y}\right)$, offers a powerful proxy in the sediment to determine the age of sediment layers and to find out whether the rain rate of particles to the seafloor and the oceanic circulation have changed with the changes from glacial to interglacial climate [7, 8]. For such investigations, the activity ratio of ${ }^{230} \mathrm{Th} /{ }^{231} \mathrm{~Pa}$ must be determined with a precision better than $1.5 \%$. Until recently ${ }^{231} \mathrm{~Pa}$ was still measured by alpha spectrometry (by counting its daughter ${ }^{227} \mathrm{Th}$ ), which requires large amounts of samples (1-2 g) to obtain a precision of only 5-10\%. 
In this paper, analytical procedures, developed in our laboratory prior to $\mathrm{Pu}, \mathrm{Am}, \mathrm{U}, \mathrm{Th}, \mathrm{Pa}$ determination in different environmental matrices by ICP-MS, are widely described. Accuracy of obtained results are discussed; particular attention is given to $\mathrm{Pu}$ isotope ratios.

\section{EXPERIMENTAL SECTION}

\subsection{Instrumentation}

The SF ICP-MS is an axiom single collector (VG Elemental, Winsford, Cheshire, UK). This mass spectrometer is equipped with a double-focusing magnetic sector mass analyzer of forward geometry. For sample introduction, a PFA microconcentric nebulizer allowing the uptake of $50 \mu \mathrm{L} \cdot \mathrm{min}^{-1}$ of sample was used. The mass spectrometer is installed in a class M 4.5 clean room.

All ICP-MS data were acquired by E-scanning in low resolution mode $(\mathrm{m} / \Delta \mathrm{m}=400)$. Sequential measurements at the different masses of interest were carried out in the peak-jumping mode. Isotope ratio bias is determined using the uranium reference material U-030 and this correction is applied to all isotope ratio measurements for systematic errors arising from mass discrimination. It was assumed that mass bias is the same for plutonium and uranium, thorium and protactinium. At low count rates, the signal loss due to detector dead time is not significant; consequently no dead time correction was necessary.

The different isotope concentrations were calculated by means of the isotope dilution mass spectrometry standard equation $[9,10,11]$.

\subsection{Chemical preparation}

\subsubsection{Pu analytical procedure}

1 to $100 \mathrm{~g}$ of ash samples were added a known amount of the ${ }^{242} \mathrm{Pu}$ spike solution. The samples were previously ached at $500{ }^{\circ} \mathrm{C}$ to decompose the organic matter. The ash samples were leached in $\mathrm{HNO}_{3} / \mathrm{HCl}$ for at least eight hours. This leaching was repeated twice, a third leaching was performed again with $8 \mathrm{M} \mathrm{HNO}_{3}$. All the filtrates were combined and the leach solution was evaporated to dryness. After addition of a solution of saturated oxalic acid, Ca oxalate was precipitated at $\mathrm{pH} 1.5$ by adding ammonia to extract $\mathrm{Pu}$ and $\mathrm{Am}$. The Ca oxalate was ached to obtain $\mathrm{Ca}$ carbonate that was later dissolved into a few milliliters of concentrated $\mathrm{HNO}_{3}$. All actinides were concentrated by copreciptation with ferric hydroxide at $\mathrm{pH}$ 8.5. The precipitate was dissolved, and then a second Ca oxalate coprecipitation was carried out. This Calcium oxalate was dissolved and loaded onto a $4 \mathrm{~mL}$ bed height anion column in order to separate plutonium and americium.

In order to further purify Pu from remaining $U$ and Fe traces, the sample was loaded again onto another anionic micro column ( $2 \mathrm{~mL}$ bed height) [12]. The sample was finally gently evaporated to dryness and dissolved in 1 to $3 \mathrm{~mL}$ of $2 \% \mathrm{~m} / \mathrm{m} \mathrm{HNO}_{3}$ before ICP-MS measurement. It is important to have a final plutonium fraction as free as possible of uranium to avoid peak overlap on ${ }^{239} \mathrm{Pu}$ due to uranium hydride specie $\left({ }^{238} \mathrm{U}^{1} \mathrm{H}^{+}\right)[4,13]$.

\subsubsection{U, Th, Pa analytical procedure}

The chemical protocol for the purification of $U$ and Th long live radionuclides from marine sediments is adapted from the protocol developed by Fleisher and Anderson [14]. $300 \mathrm{mg}$ of dried sediment were spiked with a known amount of ${ }^{236} \mathrm{U}$ (ca. $2 \mathrm{ng}$ ), ${ }^{233} \mathrm{~Pa}$ (ca. $5 \mathrm{pg}$ ) and ${ }^{229} \mathrm{Th}(c a .30 \mathrm{pg})$ spikes. A few ml of concentrated $\mathrm{HCl}$ were added to eliminate carbonates. When the solution was dried to a semi-solid mixture, $10 \mathrm{ml}$ of $\mathrm{HClO}_{4}$ and a few $\mathrm{ml}$ of concentrated $\mathrm{HNO}_{3}$ were added. When $\mathrm{HClO}_{4}$ was fuming, the beakers were covered with a Teflon lid so that the perchloric acid refluxed during about one half hour. Then a few $\mathrm{ml}$ of concentrated HF were added to the hot solution. This cycle, refluxing - followed by HF addition, was repeated 3 times, until a complete dissolution of the sediment. The refluxing step 
allows the spike-sample equilibration and a complete mineralization of the organic matter without the formation of fluoride complexes. The mineralization was achieved by washing several times the beaker walls with concentrated $\mathrm{HNO}_{3}$. After complete dissolution and evaporation to nearly dryness, the sample was dissolved in $\mathrm{HCl}$. An aliquot, corresponding to nearly $0.3 \mathrm{mg}$ of sediment, was used for direct measurements of ${ }^{238} \mathrm{U}$ and ${ }^{232} \mathrm{Th}$, after addition of ${ }^{236} \mathrm{U}$ (ca. $2 \mathrm{ng}$ ) and ${ }^{229} \mathrm{Th}$ (ca. $30 \mathrm{pg}$ ) without any further purification.

The following purification steps of ${ }^{231} \mathrm{~Pa},{ }^{230} \mathrm{Th}$ and ${ }^{234} \mathrm{U}$ were performed on the remaining solution. By adding $\mathrm{NH}_{4} \mathrm{OH}$ to $\mathrm{pH} 7-8$, Th, $\mathrm{U}$ and Pa were co-precipitated with iron hydroxide. The precipitates were cleaned by successive dissolutions and reprecipitations, and then dissolved with concentrated $\mathrm{HCl}$ in order to obtain an $8 \mathrm{M} \mathrm{HCl}$ solution. Th and $\mathrm{U}$ were separated from Pa by anion exchange. Under $8 \mathrm{M} \mathrm{HCl}$ condition, Th passes through the column, whereas $\mathrm{U}$ and $\mathrm{Pa}$ are adsorbed. $\mathrm{Pa}$ was then eluted with conc. $\mathrm{HCl}-0.13 \mathrm{~N} \mathrm{HF}$. To further purify Pa, the Pa elutes were dried and passed through a silica gel resin, fixation and desorption of Pa were followed by gamma counting. The final Pa solutions were evaporated in a Teflon beaker, dissolved again into a $1 \% \mathrm{HNO}_{3}-\mathrm{HF}$ mixture. $\mathrm{U}$ and Th fractions were combined for a further purification through a $\mathrm{HNO}_{3}$ anion column. The $\mathrm{U}$ and Th were eluted in a Teflon beaker, evaporated and dissolved into a $1 \% \mathrm{HNO}_{3}$-conc $\mathrm{HF}$ mixture.

All final fractions were filtered through $0.2 \mu \mathrm{m}$ filters to eliminate potential remaining particles before any SF ICP-MS measurement. For each analysis batch, an overall procedural blank was also carried out.

\section{RESULTS}

\subsection{Pu concentration and isotope ratios in environnemental samples}

Examples of $\mathrm{Pu}$ concentration and ${ }^{240} \mathrm{Pu} /{ }^{239} \mathrm{Pu}$ isotope ratios determined in different reference materials and field samples are given in table 1.

The experimental values achieved for the reference materials in our laboratory are in good agreement with the IAEA $95 \%$ confidence limits.

For field samples collected in different French nuclear sites, the values obtained by ICP-MS were compared to the values obtained by alpha spectrometry. Both series of values show good agreement.

As far as the ${ }^{240} \mathrm{Pu} /{ }^{239} \mathrm{Pu}$ ratios are concerned, very few values can be found in the literature because most of related studies are carried out by alpha spectrometry. The ratio determined in our laboratory for the IAEA-134 cockle flesh $(0.219 \pm 0.006$ and $0.207 \pm 0.002)$ was compared to the value published by Lee et al $(0.212 \pm 0.008)$ [15]. Both values were found to be in good agreement.

All the isotope ratios determined in the field samples collected in France are higher than the global fallout ${ }^{240} \mathrm{Pu} /{ }^{239} \mathrm{Pu}$ ratio $(0.176 \pm 0.014)[16,17]$.

\section{$3.2{ }^{231} \mathrm{~Pa} /{ }^{230} \mathrm{Th}$ activity ratios in marine sediments of Cederawasi Bay (Indonesian Archipelago)}

Naturally-occurring radionuclides are often used to study processes in the ocean because of their well-known sources. Activity ratios of two radionuclides, ${ }^{231} \mathrm{~Pa}$ and ${ }^{230} \mathrm{Th}$, have been extensively used to study boundary scavenging. Indeed the basin-wide distribution of ${ }^{231} \mathrm{~Pa}$ seems to be controlled by removal at ocean margins, whereas ${ }^{230} \mathrm{Th}$ input to the sediment is mainly linked to the local flux of particles. This difference is caused by differences in reactivity between these two elements. As the production rate ratio of ${ }^{231} \mathrm{~Pa}$ to ${ }^{230} \mathrm{Th}$ in the water column is constant, 0.093 , the departure of this value is a key to estimate scavenging intensity. Nevertheless, a major limitation of the use of ${ }^{231} \mathrm{~Pa} /{ }^{230} \mathrm{Th}$ is the low level of ${ }^{231} \mathrm{~Pa}$ usually encountered in marine sediments. The recent development of SF ICP-MS offers an interesting opportunity to measure accurately and precisely this radionuclide on small samples. This motivated the present attempt to measure ${ }^{231} \mathrm{~Pa} /{ }^{230} \mathrm{Th}$ activity ratios at LMRE.

The accuracy and precision of the measurement of naturally occurring radionuclides like uranium was previously assessed at LMRE by participating to different interlaboratories calibration exercises $[18,19]$. 
For this development, we used surface sediments collected along a depth transect off Cederawasi Bay (Wepama cruise, May 2001). ${ }^{231} \mathrm{~Pa}$ activity measured in each transect is expressed in disintegration per minute per gram of sample $\left(\mathrm{dpm} . \mathrm{g}^{-1}\right)$ in table 2. Two different sub-samples of the transect were analyzed separately, one by alpha spectrometry (italic characters) and the other one by SF ICP-MS. ICP-MS (bold characters).

Although sample sizes were smaller for ICP-MS than for alpha spectrometry, all ${ }^{231} \mathrm{~Pa}$ and Th results show relative good agreement. Agreement could be further improved with longer ICP-MS acquisition times and complete cross calibration of the faraday cup and electron multiplier versus the masses. As a matter of fact, the Axiom SC spectrometer allows the detection of most abundant ions on the faraday cup and minor isotopes on the electron multiplier.

The treatment of a few hundred milligrams of sediment for SF ICP-MS allows a much more easier chemical preparation and lower procedural blanks as less reagents are necessary.

In this first attempt only the 1 and $7 \mathrm{~cm}$ layers sub-samples were analyzed, additional samples should be treated in order to set up a complete oceanographic study.

\section{CONCLUSION}

In addition to the accurate and precise activity of plutonium isotopes $\left({ }^{239} \mathrm{Pu},{ }^{240} \mathrm{Pu},{ }^{241} \mathrm{Pu}\right)$ in environmental samples, SF ICP-MS measurements allow to give further information by determining also the ${ }^{240} \mathrm{Pu} /{ }^{239} \mathrm{Pu}$ ratio. This information can also help in identifying the source of the $\mathrm{Pu}$ introduction in the environment.

Data determined in this experiment show that ${ }^{231} \mathrm{~Pa}$ and ${ }^{230} \mathrm{Th}$ in marine sediments can be precisely and accurately measured by SF ICP-MS. In this particular application field, the next step of this work will be to analyze more samples by SF ICP-MS in order to draw a complete conclusion concerning the oceanographic study itself.

Table 1. ${ }^{239+240} \mathrm{Pu}$ and ${ }^{241} \mathrm{Pu}$ activity in environmental samples obtained by SF ICP-M, expanded uncertainty k=2. * Expected values are IAEA 95 \% confidence levels for reference materials, or values previously determined by alpha spectrometry for the field samples.

\begin{tabular}{|c|c|c|c|c|c|c|c|c|}
\hline Sample ID & $\begin{array}{c}\text { Sample } \\
\text { size (kg) }\end{array}$ & $\begin{array}{c}{ }^{239} \mathrm{Pu} \\
\left(\mathrm{mBq} \cdot \mathrm{kg}^{-1}\right)\end{array}$ & $\begin{array}{c}{ }^{240} \mathrm{Pu} \\
\left(\mathrm{mBq} \cdot \mathrm{kg}^{-1}\right)\end{array}$ & $\begin{array}{c}{ }^{239+240} \mathrm{Pu} \\
\left(\mathrm{mBq} \cdot \mathrm{kg}^{-1}\right)\end{array}$ & $\begin{array}{c}{ }^{239+240} \mathrm{Pu} \\
\text { Expected value * } \\
\left(\mathrm{mBq} \cdot \mathrm{kg}^{-1}\right)\end{array}$ & $\begin{array}{l}\left({ }^{240} \mathrm{Pu} /{ }^{239} \mathrm{Pu} \text { ) }\right. \\
\text { (atom ratio) }\end{array}$ & $\begin{array}{c}{ }^{241} \mathrm{Pu} \\
\left(\mathrm{Bq} \cdot \mathrm{kg}^{-1}\right)\end{array}$ & $\begin{array}{c}{ }^{241} \mathrm{Pu} \\
\text { expected } \\
\text { value * } \\
\left(\mathrm{Bq} \cdot \mathrm{kg}^{-1}\right)\end{array}$ \\
\hline \multicolumn{9}{|c|}{ Reference materials } \\
\hline IAEA 134 & 0.004 & $7862 \pm 426$ & $6325 \pm 472$ & $14187 \pm 636$ & $13800-16200$ & $0.219 \pm 0.120$ & & \\
\hline IAEA 134 & 0.004 & $8882 \pm 288$ & $6768 \pm 220$ & $15650 \pm 362$ & $13800-16200$ & $0.207 \pm 0.004$ & & \\
\hline IAEA soil 6 & 0.011 & $585 \pm 22$ & $419 \pm 20$ & $1004 \pm 30$ & $962-1110$ & $0.196 \pm 0.004$ & & \\
\hline IAEA 375 & 0.121 & $129 \pm 12$ & $129 \pm 14$ & $258 \pm 19$ & $260-340$ & $0.271 \pm 0.006$ & & \\
\hline IAEA 367 & 0.005 & $16500 \pm 3400$ & $18600 \pm 3800$ & $35100 \pm 5099$ & $34400-39800$ & $0.306 \pm 0.002$ & $166 \pm 17$ & $154-190$ \\
\hline IAEA 367 & 0.003 & $17000 \pm 2000$ & $19100 \pm 2000$ & $36200 \pm 2828$ & $34400-39800$ & $0.305 \pm 0.004$ & $198 \pm 10$ & $154-190$ \\
\hline \multicolumn{9}{|c|}{ Field samples } \\
\hline SOIL0031V & 0.013 & $124 \pm 4$ & $86 \pm 4$ & $211 \pm 12$ & $219 \pm 8$ & $0.206 \pm 0.020$ & & \\
\hline PRAIR0102B & 0.039 & $12.7 \pm 1.9$ & $10.5 \pm 1.5$ & $23 \pm 5$ & $21.1 \pm 2.6$ & $0.223 \pm 0.008$ & & \\
\hline FUC0102O & 0.046 & $56.5 \pm 5.5$ & $54.8 \pm 5.4$ & $111.3 \pm 15.4$ & $119 \pm 6$ & $0.264 \pm 0.010$ & & \\
\hline SED0014O & 0.021 & $869 \pm 68$ & $729 \pm 59$ & $1597 \pm 180$ & $1476 \pm 245$ & $0.239 \pm 0.005$ & $27955 \pm 3049$ & \\
\hline SED0014M & 0.100 & $793 \pm 42$ & $676 \pm 38$ & $1469 \pm 114$ & $1476 \pm 245$ & $0.242 \pm 0.005$ & $26307 \pm 1851$ & \\
\hline
\end{tabular}


Table 2. ${ }^{238} \mathrm{U},{ }^{232} \mathrm{Th},{ }^{230} \mathrm{Th},{ }^{231} \mathrm{~Pa}$ in surface marine sediment (layers 1 and $7 \mathrm{~cm}$, core KTB05, $0^{\circ} 48.31 \mathrm{~S}, 134^{\circ} 38.79 \mathrm{E}$, Cederawasi Bay, Indonesian Archipelago): comparison of values obtained by SF-ICP-MS (bold characters, expanded uncertainty $\mathrm{k}=2$ ) and by obtained by alpha spectrometry (italic characters, 2 sigma error).

\begin{tabular}{cccccc}
\hline Sample ID & $\begin{array}{c}\text { Sample } \\
\text { Size }(\mathrm{g})\end{array}$ & $\begin{array}{c}{ }^{238} \mathrm{U} \\
\left(\mathrm{dpm} . \mathrm{g}^{-1}\right)\end{array}$ & $\begin{array}{c}{ }^{232} \mathrm{Th} \\
\left(\mathrm{dpm} . \mathrm{g}^{-1}\right)\end{array}$ & $\begin{array}{c}{ }^{230} \mathrm{Th} \\
\left(\mathrm{dpm} . \mathrm{g}^{-1}\right)\end{array}$ & $\begin{array}{c}{ }^{231} \mathrm{~Pa} \\
\left(\mathrm{dpm} . \mathrm{g}^{-1}\right)\end{array}$ \\
\hline WEPAMA 5-1 & $\mathbf{0 . 3 0 7 1}$ & $\mathbf{0 . 7 7 4} \pm \mathbf{0 . 0 3 1}$ & $\mathbf{1 . 2 9} \pm \mathbf{0 . 0 5}$ & $\mathbf{2 . 2 9} \pm \mathbf{0 . 0 9}$ & $\mathbf{0 . 1 5 5} \pm \mathbf{0 . 0 0 1}$ \\
& 1.9 & $0.877 \pm 0.046$ & $1.28 \pm 0.07$ & $1.80 \pm 0.09$ & $0.13 \pm 0.07$ \\
\hline WEPAMA 5-7 & $\mathbf{0 . 3 0 5 2}$ & $\mathbf{0 . 7 9 6} \pm \mathbf{0 . 0 3 0}$ & $\mathbf{1 . 3 6} \pm \mathbf{0 . 0 5}$ & $\mathbf{2 . 3 6} \pm \mathbf{0 . 0 9}$ & $\mathbf{0 . 1 4 0} \pm \mathbf{0 . 0 0 1}$ \\
& 1.7 & $0.84 \pm 0.05$ & $1.30 \pm 0.09$ & $1.80 \pm 0.110$ & $0.13 \pm 0.07$ \\
\hline
\end{tabular}

\section{Acknowledgements}

Marine sediments were collected during IMAGES-WEPAMA cruise on board n.o. Marion Dufresne. This work was supported by the CNRS-INSU and IPEV. This is a UMR5805 EPOC and LMRE contribution.

\section{References}

[1] M. Agarande, E. Barker, M. Curtis, R. Lukey, Radioprotection Colloques, V.37, C1, (2002), 945-950.

[2] J. Moreno, J. J. LaRosa, P. R. Danesi, K. Burns, P. DeRegge, N. Vajda, M. Sinojmeri, Radioactivity and Radiochemistry, Vol. 9, No. 2, (1998), 35-44.

[3] C. Kim, R. Seki, S. Morita, S. Yamasaki, A. Tsumura, Y. Takaku, Y. Igarashi, M. Yamamoto, J. Anal. At. Spectrom. 6, (1991) 205-209.

[4] S. Stürup, H. Dahlgaard, S. C. Nielsen, J. Anal. At. Spectrom. 13, (1998) 1321-1326.

[5] Y. Muramatsu, S. Uchida, K. Tagami, S. Yoshida, T. Fujikawa, J. Anal. At. Spectrom. 14, (1999), 859-865.

[6] J. K. Cochran, In Uranium-series Disequilibrium: Applications to Earth, Marine, and Environmental Sciences, Ivanovich R.S. (Editor), Clarendon Press, Oxford (1992), 334-395.

[7] R. F. Anderson, M. P. Bacon, P. G. Brewer, Earth Planet. Sci. Lett. 66, (1983), 73-90.

[8] E.-F. Yu, R. Francois, M. P. Bacon, Nature 379, (1996), 689-694.

[9] K. G. Heumann, F. Adams, R. Gijbels, R. Van Grieken, Inorganic Mass spectrometry-Isotope dilution mass spectrometry, Wiley, NY (USA), (1988) 301-376.

[10] M. Sargent, R. Harte, C. Harrington, Guidelines for achieving high accuracy in isotope dilution mass spectrometry, RSC, Cambridge (UK), (2002).

[11] M. Agarande, S. Benzoubir, P. Bouisset, D. Calmet, Applied Radiation and Isotopes 55, (2001), 161-165.

[12] M. Agarande, S;. Benzoubir, A. M. Neiva Marques, P. Bouisset, J. Environ. Radioactivity, 72, (2004) 169-176.

[13] R.F. Chiappini, J. M. Taillade, S. Brebion, J. Anal. At. Spectrom., 11, (1996), 497-503.

[14] M. Q. Fleisher and R. F. Anderson, Deep-Sea Res. II 50, (2003), 693-712.

[15] S. H. Lee, J. Gastaud, J.J. La Rosa, L. Liong Wee Kwong, P. P. Povinec, E. Wyse, L. K. Fifield, P. A. Hausladen, L. M. Di Tada, G. M. Santos, Journal of Radiaoanalytical and Nuclear Chemistry, Vol. 248 No. 3, (2001), 757-764.

[16] K. O. Buesseler,, J. E. Halverson, J. Environ. Radioactivity. 5 (1987) 425-444.

[17] P. W. Krey, E. P. Hardy, C. Pachucki, F. Rourke, J. Coluzza, W. K. Benson, Proceedings of a symposium on Transuranium nuclides in the environment. IAEA-SM-199-39, (1976) 671-678.

[18] A. Held, A. Alonso, W. De Bolle, A. Verbruggen, R. Wellum, Nusimep-3, Report to participants, EUR 2077 EN, (2002).

[19] G. Granier, Note technique DPRC/CETAMA/2003/03, (2003). 